\title{
AMADURECIMENTO DA BANANA-PRATA CLIMATIZADA EM DIFERENTES DIAS APÓS A COLHEITA
}

\author{
Characterization of 'prata' bananas, acclimatized at different time intervals after the harvest
}

\author{
Cíntia de Souza Silva ${ }^{1}$, Luciana Costa Lima ${ }^{2}$, Haydée Siqueira Santos ${ }^{1}$, Elisangela Clarete Camili \\ Cássia Regina Yuriko Ide Vieira ${ }^{2}$, Cristhiane da Silva Martin'1, Rogério Lopes Vieites ${ }^{3}$
}

\begin{abstract}
RESUMO
O amadurecimento induzido por climatização em bananas, é um procedimento que tem sido largamente utilizado. Ele proporciona uma maturação uniforme, já que a fruta apresenta maturação desuniforme em vista da formação dos frutos em pencas com diferentes idades. No entanto, não há para todas as cultivares de banana, estudos específicos em relação ao tempo entre a colheita e a climatização que possa afetar a qualidade dos frutos. Desta forma, com o presente trabalho objetivou-se avaliar mediante as características físicas, químicas e fisiológicas a qualidade da banana - prata climatizada em diferentes dias entre a colheita e a climatização. Foram testados três diferentes dias de climatização sendo 1, 2 e 3 dias após a colheita. Ao final da climatização, os frutos foram armazenados em temperatura ambiente por um período de 5 dias. As análises realizadas foram: perda de massa, coloração da casca, respiração, firmeza, pH, sólidos solúveis, acidez titulável e amido. Frutas climatizadas 1 dia após a colheita apresentaram-se, no $1^{\circ}$ dia de armazenamento, com menor perda de massa, mais verdes, com maior liberação de $\mathrm{CO}_{2}$ mais firmes, com menores teores de sólidos solúveis e maior porcentagem de amido, quando comparados àqueles climatizados aos 2 e 3 dias após a colheita. Essa diferença foi reduzida com o decorrer do armazenamento praticamente se igualando os tratamentos ao final do armazenamento.
\end{abstract}

Termos para indexação: Etileno, qualidade, Musa sp.

\begin{abstract}
The ripening of bananas, as induced by acclimatization, it is a procedure that has been used widely. It provides an uniform maturation, so overcoming the irregular maturation due to the formation of the fruits in bunches with different ages. Nonetheless, there are no specific studies relating the quality of the fruits and the time between the harvest and the acclimatization. In this sense, the present work used the physico-chemical characteristics of the 'prata' bananas to evaluate their quality when submitted to acclimatization at 1,2 and 3 days after harvest. By the end of the acclimatization, the fruits were stored for 5 days in environmental temperature. The accomplished analyses were: weight loss, coloration of the peel, respiration, texture, $\mathrm{pH}$, soluble solids, titratable acidity and starch. After one day of storage, the fruits which were acclimatized for 1 day after harvest presented smaller weight loss, larger liberation of $\mathrm{CO} 2$, smaller contents of soluble solids, larger percentage of starch and were greener and firmer than those acclimatized 2 and 3 days after the harvest. The difference was reduced as the time of storage increased and no significant differences among the treatments were observed after 5 days of storage.
\end{abstract}

Index terms : ethylene, quality, Musa sp.

(Recebido para publicação em 14 de janeiro de 2004 e aprovado em 20 de outubro de 2004)

\section{INTRODUÇÃO}

Originária do Oriente (MOREIRA, 1987), a banana (Musa ssp) constitui uma das principais culturas das zonas tropicais e semitropicais (CHITARRA \& CHITARRA, 1984), sendo considerada a fruta mais consumida no mundo. Com uma produção média de 6,5 milhões de ton/ano, o Brasil é responsável por cerca de $9,4 \%$ da produção mundial, sendo superado somente pela Índia (FAO, 2004). Dentre as diversas variedades de banana, a 'Prata' representa grande importância, sendo a mais produzida e consumida no Brasil (IBGE, 1997).

No que se refere à qualidade da fruta, o grande problema da bananicultura brasileira, consiste no manejo do produto a partir de sua colheita: transportes, embalagem, climatização, manuseio e na própria residência do consumidor. A falta de cuidados no manejo pós-colheita é responsável pela desvalorização da banana no mercado interno e pela perda de oportunidade de exportação da fruta brasileira (LICHTEMBERG, 1999).

A fruta que se destina ao mercado in natura deve apresentar alto padrão de qualidade e características próprias para a comercialização, com amadurecimento uniforme. A banana, sendo uma fruta climatérica (PALMER, 1981; SIMMONDS, 1973), é colhida ainda verde. Naturalmente, seu amadurecimento é desuniforme em vista da formação dos frutos em pencas, com diferentes idades

\footnotetext{
${ }^{1}$ Aluna do curso de Mestrado em Agronomia/Horticultura - FCA/UNESP - Botucatu, SP - Rua Arapongas, 89, apto 22 - Vinhedo, SP - 13.280-000 cintiasilva@fca.unesp.br

${ }^{2}$ Aluna do curso de Doutorado em Agronomia/Horticultura - FCA/UNESP - Botucatu, SP.

${ }^{3}$ Professor Adjunto do Departamento de Gestão e Tecnologia Agro-Industrial - Pós-Colheita de Frutas e Hortaliças - FCA/UNESP - Botucatu, SP.
} 
(ROCHA, 1984). A climatização é uma técnica que, além de proporcionar um amadurecimento mais uniforme, tem a finalidade de desencadear e acelerar o processo de amadurecimento. Neste sistema, a temperatura, umidade do ar e concentração de gases $\left(\mathrm{CO}_{2}\right.$ e $\left.\mathrm{O}_{2}\right)$ são controlados por meio de aparelhos e procedimentos específicos, ocorrendo aplicações pré-determinadas de um gás indutor do amadurecimento.

O etileno é considerado um hormônio natural do amadurecimento das frutas e o aumento na sua biossíntese, até concentrações que estimulam o processo, é o evento que marca a transição entre as fases de crescimento e senescência no fruto (CHITARRA \& CHITARRA, 1990). Portanto, a aplicação de etileno exógeno na fase préclimatérica da fruta desencadeia o seu processo de amadurecimento (CASTRO, 1992). Bleinroth (1984) e Rocha (1984) sugerem que o etileno seja aplicado na razão de 1/ $1000 \mathrm{em} 1 \mathrm{ppm}$. Ainda Chitarra \& Chitarra (1994), propõem que a taxa normal de etileno requerido em câmaras seja de $10 \mathrm{ppm}$, podendo chegar a $1000 \mathrm{ppm}$.

Porém, a eficiência da climatização pode estar associada a diversos fatores que afetam seu potencial. ISO (1977) define que deficiências de coloração da casca da banana, após a sua climatização, podem estar associados à demora entre a colheita e o embalamento das frutas. Ainda Simão (1998) recomenda intervalo máximo de 72 horas entre a colheita e o armazenamento das frutas em local ventilado ou frigorificado, garantindo que quanto menor for esse intervalo, maior será a qualidade das frutas.

Portanto, com o presente trabalho busca-se caracterizar a banana-prata climatizada mediante análises físicas, químicas e fisiológicas levando-se em consideração diferentes dias entre a colheita e a climatização. Tal conhecimento é de fato importante já que na maioria das vezes o local onde ocorre a climatização se encontra distante do local de produção da banana.

\section{MATERIAL E MÉTODOS}

A banana utilizada no experimento foi da variedade Prata (Musa AAB), proveniente da cidade de Eldorado -SP, localizada a latitude 24,52 sul, longitude 48,12 oeste e altitude de 62 metros (IBGE, 2002).

Os cachos foram colhidos e as frutas foram despencadas e selecionadas, sendo acondicionadas em caixas de madeira, contendo em média $22 \mathrm{Kg}$.

Em seguida, foram transportadas em caminhão aberto, durante 10 horas, ate a cidade de Botucatu -SP, sendo acondicionadas em barracão coberto e separadas em 3 lotes, definindo-se os seguintes tratamentos:
Tratamento A: climatização realizada 1 dia após a colheita; Tratamento B: climatização realizada 2 dias após a colheita e Tratamento C: climatização realizada 3 dias após a colheita.

$\mathrm{O}$ processo de climatização se estendeu por um período de 2 dias com os seguintes parâmetros: Temperatura: 18 a $19^{\circ} \mathrm{C}$; Umidade relativa: 85\%, Exaustão: 1 hora / 24 horas; Gás ativador do amadurecimento: uma carga de 1000 ppm de Etil 5 (95\% de nitrogênio e 5\% de etileno) a cada 24 horas.

Ao final da climatização, cada lote foi levado ao Laboratório de Frutas e Hortaliças do Departamento de Gestão e Tecnologia Agroindustrial da UNESP de Botucatu. Para obtenção dos dados, o experimento foi dividido em 2 grupos: o grupo 1, submetido a análises não destrutivas com um total de 10 pencas/tratamento e o grupo 2, submetido a análises destrutivas com um total de 9 pencas/ tratamento. A avaliação de cada lote foi conduzida por um período de 5 dias à temperatura ambiente $\left(25^{\circ} \mathrm{C} \pm 2^{\circ} \mathrm{C}\right)$, sendo que para as análises destrutivas foram utilizadas 3 pencas/dia avaliadas no $1^{\circ}, 3^{\circ}$ e $5^{\circ}$ dia após a climatização. Cada penca correspondeu a uma repetição.

Os frutos do grupo 1 (análises não destrutivas) foram avaliados segundo as variáveis:

Respiração - a determinação da taxa de respiração foi efetuada de forma indireta em respirômetro, de acordo com metodologia adaptada de Bleinroth et al. (1976). A técnica consistiu no acondicionamento da banana em campânula de vidro durante 1 hora, sob fluxo contínuo de ar isento de $\mathrm{CO}_{2}$. A taxa respiratória expressa em $\mathrm{CO}_{2} \cdot \mathrm{Kg}$ de fruta $^{-1}$. hora ${ }^{-1}$ foi determinada pela titulação de solução de $\mathrm{KOH}$ a $0,1 \mathrm{~N}$, com solução de $\mathrm{HCl} 0,1 \mathrm{~N}$, calculando-se o peso de $\mathrm{CO}_{2}$ liberado pela respiração dos frutos.

Perda de massa - em porcentagem, por pesagem direta, considerando-se a massa das frutas antes da climatização e a cada período de avaliação, em balança digital semi-analítica (modelo Gehaka BG 440);

Coloração da casca - definida por uma escala subjetiva de notas, considerando o grau de coloração da casca dos frutos segundo Soto-Ballestero (1992), em que 1 (verde), 2 (verde-claro), 3 (verde- amarelado), 4 (mais amarelado que verde), 5 (amarelo com pontas verde), 6 (totalmente amarelo) e 7 (amarelo com manchas marrom).

Já os frutos do grupo 2 (análises destrutivas) foram avaliados segundo:

Firmeza - medida nos frutos inteiros sem casca. O aparelho utilizado foi o texturômetro (Stevens - LFRA Texture analyser), com ponta de prova - TA 9/1000, distância de penetração de $20 \mathrm{~mm}$ e velocidade de $2,0 \mathrm{~mm} / \mathrm{seg}$. Os resultados foram expressos em lb.pol ${ }^{-2}$; 
Sólidos solúveis totais - em refratômetro manual digital, marca Atago, segundo a metodologia de Carvalho et al. (1990);

Amido - em porcentagem, pelo método de Lane Enyon (AOAC, 1992).

pH - determinado potenciometricamente em pHmetro Tecnal TEC-2, no suco da fruta, obtido pela trituração de 3 frutas por repetição, segundo a metodologia de Carvalho et al. (1990);

Acidez total titulável - por titulação, empregandose $\mathrm{NaOH}(0.1 \mathrm{~N})$ para titulação até atingir $\mathrm{pH}$ de 8,00 . O resultado foi expresso em $\mathrm{g}$ ácido málico. $100 \mathrm{~g}$ de polpa ${ }^{-1}$ (CARVALHO et al., 1990);

Em todas as análises foram utilizadas 3 repetições com 3 frutas como unidade experimental. $\mathrm{O}$ delineamento utilizado foi o inteiramente casualizado e após análise de variância as médias foram comparadas pelo teste de Tukey ao nível de 5\% de probabilidade, de acordo com o recomendado por Gomes (1987).

\section{RESULTADOS E DISCUSSÃO}

Logo após a colheita (análise preliminar), as bananas apresentavam as seguintes características: cor da casca, nota 1 (desvio padrão 0); respiração $6,00 \mathrm{~mL}$ $\mathrm{CO}_{2} \cdot \mathrm{Kg}$ fruta $^{-1} \cdot \mathrm{h}^{-1}$ (desvio padrão 0,20 ); firmeza dos frutos $1.006 \mathrm{lb} . \mathrm{pol}^{-2}$ (desvio padrão 15,04); pH 5,70 (desvio padrão 0 ); sólidos solúveis $3,20^{\circ}$ Brix (desvio padrão 0,23 ); acidez titulável, $1,17 \mathrm{~g}$ de ácido málico. $100 \mathrm{~g}$ de polpa ${ }^{-1}$ (desvio padrão 0,04 ) e amido $18 \%$ (desvio padrão 0,40 ).

$\mathrm{O}$ amadurecimento é o resultado de mudanças complexas que ocorrem no fruto. As principais mudanças que podem ser observadas são: aumento de taxa respiratória, aumento na produção de etileno, aumento na concentração de açúcares, solubilização das substâncias pécticas, degradação de pigmentos, aumento na concentração de fenólicos e ácidos, produção de voláteis, variações nos teores de enzimas, vitaminas, minerais e mudanças na permeabilidade dos tecidos (CHITARRA \& CHITARRA, 1984).

$\mathrm{Na}$ banana estas alterações são bem definidas, já que se trata de uma fruta climatérica, ressaltando-se, como fenômeno metabólico de maior importância, a respiração. Essa respiração apresenta características marcantes, sendo o pico climatérico o momento de maior liberação de $\mathrm{CO}_{2}$ pela fruta, marcando o início de senescência da mesma.

Pelos dados apresentados na Tabela 1, podemos verificar que as bananas do tratamento A (climatizadas 1 dia após a colheita), quando avaliadas no $1^{\circ}$ dia de armazenamento, provavelmente estavam no seu pico climatérico quando foram retiradas da câmara, pois apresentavam teor de $\mathrm{CO}_{2}$ elevado $\left(313,3 \mathrm{~mL} \mathrm{CO}_{2} . \mathrm{Kg}\right.$ fruta $\left.^{-1} . \mathrm{h}^{1}\right)$. Já as bananas do tratamento B (climatizadas 2 dias após a colheita) e C (climatizadas 3 dias após a colheita) possivelmente já estavam na fase pós-climatérica (início da senescência) após remoção das câmaras, devido aos teores de $\mathrm{CO}_{2}$ apresentarem-se significativamente inferiores aos do tratamento A, 135,7 $\mathrm{mL} \mathrm{CO}_{2} . \mathrm{Kg}_{\text {fruta }}{ }^{-1} \cdot \mathrm{h}^{-1}$ e $196,3 \mathrm{~mL} \mathrm{CO}_{2}$. $\mathrm{Kg}$ fruta $^{-1} \cdot \mathrm{h}^{-1}$, respectivamente. Segundo Lichtemberg (1999), a concentração de 1000 ppm de etileno proporciona taxa respiratória de 70 a $300 \mathrm{mg} \mathrm{CO}_{2} . \mathrm{Kg}_{\text {fruta }}{ }^{-1} \cdot \mathrm{h}^{-1}$, valores estes concordantes aos encontrados no presente trabalho.

Esse dado sugere que as frutas dos tratamentos $\mathrm{B}$ e C tiveram seu amadurecimento acelerado em relação às frutas do tratamento $\mathrm{A}$, devido, provavelmente, a seu acondicionamento em condições ambientais $\left(25^{\circ} \mathrm{C} \pm 2^{\circ} \mathrm{C}\right)$ durante um maior período de tempo. Assim, as frutas do tratamento A, mantidas em ambiente controlado durante a climatização $\left(18-19^{\circ} \mathrm{C}\right.$ e 85 UR\%), apesar de serem induzidas ao amadurecimento devido à aplicação de etileno, tiveram seu amadurecimento retardado, em comparação às frutas submetidas aos demais tratamentos.

TABELA 1 -Variação média da respiração $\left(\mathrm{mL} \mathrm{CO}_{2} \cdot \mathrm{Kg}_{\text {fruta }}{ }^{-1} \cdot \mathrm{h}^{-1}\right)$ de banana prata submetida à climatização* .

\begin{tabular}{ccccc}
\hline $\begin{array}{c}\text { Tratamentos } \\
\text { (dias entre colheita e } \\
\text { climatização) }\end{array}$ & \multicolumn{3}{c}{ Dia de armazenamento após climatização } & \\
\cline { 2 - 4 } & $\mathbf{1}^{\mathbf{0}}$ & $\mathbf{3}^{\mathbf{0}}$ & $\mathbf{5}^{\mathbf{0}}$ & $\mathbf{C V}(\boldsymbol{\%})$ \\
\hline $\mathrm{A}(1 \mathrm{dia})$ & $313,3 \mathrm{Aa}$ & $221,7 \mathrm{Ab}$ & $160,7 \mathrm{Ac}$ & 1,52 \\
$\mathrm{~B}(2 \mathrm{dias})$ & $135,7 \mathrm{Cb}$ & $169,6 \mathrm{Ba}$ & $85,4 \mathrm{Bc}$ & 0,62 \\
$\mathrm{C}(3 \mathrm{dias})$ & $196,3 \mathrm{Ba}$ & $163,1 \mathrm{Bb}$ & $169,7 \mathrm{Ab}$ & 5,77 \\
\hline CV $(\%)$ & 0,73 & 1,73 & 7,37 & \\
\hline
\end{tabular}

Médias seguidas de mesma letra maiúscula, na vertical, e minúscula na horizontal, não diferem estatisticamente, a nível de 5\% probabilidade, pelo teste de Tukey.

* $1000 \mathrm{ppm}$ de etil $5,18-19^{\circ} \mathrm{C}, 85 \%$ de UR. 
Com os resultados apresentados neste trabalho, propõe-se que a climatização realizada 1 dia após a colheita retardou o pico climatérico dos frutos do tratamento A, ou seja, quanto menor o tempo entre a colheita e a climatização das bananas, menor a velocidade de metabolismo dos frutos. Esse dado se confirma quando relacionado aos demais parâmetros analisados neste estudo.

Conforme se observa na Tabela 2, verifica-se uma perda gradual de massa nos frutos em todos os tratamentos no decorrer do armazenamento. Este comportamento é concordante com Botelho (1996) e Chitarra \& Chitarra (1990) que relataram perda de massa dos frutos após a colheita.

A perda de massa dos frutos é associada principalmente à perda de água ocasionada tanto pela transpiração como pela respiração das frutas (SIGRIST, 1992), sendo esta perda superior quando as frutas são armazenadas em altas temperaturas e/ou baixa umidade relativa (BOTREL et al., 2001). Essa perda de massa também é acentuada quanto maior o grau de amadurecimento da fruta, chegando a níveis demasiados na senescência da fruta, quando esta não se apresenta mais apta à comercialização.

Quanto à porcentagem de perda de massa das frutas submetidas aos diferentes tratamentos, nota-se que no $1^{\circ}$ dia após o armazenamento, houve diferença significativa entre o tratamento $\mathrm{A}$ e os demais tratamentos (B e C). Explica-se este fato com base na manutenção das frutas dos tratamentos 2 e $3 \mathrm{em}$ condições ambientais durante um maior período de tempo, antes da climatização da fruta. Neste trabalho não considerou-se a possível perda de massa da fruta ocorrida durante o transporte da banana, já que as avaliações somente foram iniciadas depois da retirada das frutas da câmara de climatização.

A mudanças de coloração ocorridas durante o amadurecimento das frutas estão relacionadas com processos degradativos e/ou sintéticos dos pigmentos presentes nas frutas (CHITARRA \& CHITARRA, 1990). $\mathrm{Na}$ banana, durante o amadurecimento, a degradação da clorofila (cor verde) é intensa, ficando visível a préexistência dos pigmentos carotenóides (cor amarela a laranja) enquanto que a síntese de outros pigmentos é realizada em níveis relativamente baixos.

$\mathrm{Na}$ Tabela 3 , verifica-se que no $1^{\circ}$ dia de armazenamento, a perda da coloração verde foi mais acentuada nas frutas climatizadas 3 dias após a colheita, quando comparados àquelas climatizadas 1 dia após a colheita. Esse dado também pode ser explicado devido à manutenção das frutas dos tratamentos 2 e 3 em condições ambientais durante um maior período de tempo, antes da climatização da fruta, ocasionando uma aceleração na degradação de clorofila. No $3^{\circ}$ dia de armazenamento, as frutas que foram climatizadas 2 e 3 dias após a colheita, apresentaram-se inteiramente maduras, porém com as pontas amarronzadas (grau 7 de coloração), diferindo estatisticamente, dos frutos climatizados 1 dia após a colheita (grau 6 de coloração). No entanto, no $5^{\circ}$ dia de armazenamento, as frutas de todos os tratamentos apresentaram-se inteiramente maduras e com manhas marrons (grau 7 de coloração).

TABELA 2 - Variação média da perda massa (\%) de banana-prata submetida à climatização* .

\begin{tabular}{ccccc}
\hline $\begin{array}{c}\text { Tratamentos } \\
\text { (dias entre colheita e } \\
\text { climatização) }\end{array}$ & \multicolumn{3}{c}{ Dia de armazenamento após climatização } & \\
\cline { 2 - 4 } & $\mathbf{1}^{\mathbf{0}}$ & $\mathbf{3}^{\mathbf{0}}$ & $\mathbf{\mathbf { 5 } ^ { \mathbf { 0 } }}$ & $\mathbf{C V}(\boldsymbol{\%})$ \\
\hline $\mathrm{A}(1 \mathrm{dia})$ & $1,8 \mathrm{Aa}$ & $8,1 \mathrm{Ab}$ & $12,9 \mathrm{Ac}$ & 0,74 \\
$\mathrm{~B}(2$ dias $)$ & $2,8 \mathrm{Ba}$ & $8,1 \mathrm{Ab}$ & $14,2 \mathrm{Ac}$ & 1,05 \\
$\mathrm{C}(3$ dias $)$ & $3,1 \mathrm{Ba}$ & $8,1 \mathrm{Ab}$ & $14,7 \mathrm{Ac}$ & 1,27 \\
\hline CV $(\%)$ & 0,35 & 1,02 & 1,54 \\
\hline
\end{tabular}

Médias seguidas de mesma letra maiúscula, na vertical, e minúscula na horizontal, não diferem estatisticamente, a nível de $5 \%$ probabilidade, pelo teste de Tukey.

* $1000 \mathrm{ppm}$ de etil $5,18-19^{\circ} \mathrm{C}, 85 \%$ de UR.

Ciênc. agrotec., Lavras, v. 30, n. 1, p. 103-111, jan./fev., 2006 
TABELA 3 - Variação média da coloração (escala de notas) de banana-prata submetida à climatização* .

\begin{tabular}{ccccc}
\hline $\begin{array}{c}\text { Tratamentos } \\
\text { dias entre colheita e } \\
\text { climatização) }\end{array}$ & \multicolumn{3}{c}{ Dia de armazenamento após climatização } & \\
\cline { 2 - 4 } & $\mathbf{1}^{\mathbf{0}}$ & $\mathbf{3}^{\mathbf{0}}$ & $\mathbf{\mathbf { 5 } ^ { \mathbf { 0 } }}$ \\
\hline $\mathrm{A}(1 \mathrm{dia})$ & $2,6 \mathrm{Bc}$ & $6,0 \mathrm{Bb}$ & $7,0 \mathrm{Aa})$ \\
$\mathrm{B}(2$ dias $)$ & $3,8 \mathrm{ABb}$ & $7,0 \mathrm{Aa}$ & $7,0 \mathrm{Aa}$ & 6,07 \\
$\mathrm{C}(3 \mathrm{dias})$ & $4,6 \mathrm{Ab}$ & $7,0 \mathrm{Aa}$ & $7,0 \mathrm{Aa}$ & 8,66 \\
\hline $\mathrm{CV}(\%)$ & 6,35 & 0,14 & 0,02 & \\
\hline
\end{tabular}

Médias seguidas de mesma letra maiúscula, na vertical, e minúscula na horizontal, não diferem estatisticamente, a nível de $5 \%$ probabilidade, pelo teste de Tukey.

* $1000 \mathrm{ppm}$ de etil $5,18-19^{\circ} \mathrm{C}, 85 \%$ de UR.

Pela Tabela 4, observa-se que os valores de firmeza das frutas apresentam diferenças significativas entre os tratamentos e durante $o$ armazenamento. As frutas climatizadas 1 dia após a colheita apresentaram-se mais firmes somente no $1^{\circ}$ dia de armazenamento. No $3^{\circ}$ e $5^{\circ}$ dia após o armazenamento, não houve diferença significativa entre os tratamentos.

Contudo, pode-se observar que ocorreu redução gradual nos valores de firmeza em todos os tratamentos durante o transcorrer do armazenamento, concordando com Chitarra (1996) e Chitarra \& Chitarra (1994). Esta perda de firmeza está associada tanto à perda de água, quanto à solubilização das protopectinas existentes nas frutas. Levando-se exclusivamente em consideração a perda de água das frutas podem-se relacionar estes dados com os encontrados na Tabela 2, quando as frutas do tratamento A (climatizadas 1 dia após a colheita) apresentaram as menores perdas de massa no $1^{\circ}$ dia de avaliação, sugerindo um retardo no amadurecimento dessas frutas.

Pela Tabela 5, nota-se que no $1^{\circ}$ dia de armazenamento, o teor de sólidos solúveis do tratamento $\mathrm{A}$ é significativamente inferior aos dos tratamentos B e C. Com base nestes resultados, podemos observar que as frutas do tratamento A quando foram retiradas da câmara de climatização estavam em estádio de amadurecimento menos avançado quando comparados com as do tratamento B e C. Porém, estes valores ainda sofreram alterações com o decorrer do armazenamento se igualando ao final deste.

Com relação ao período de armazenamento, houve aumento dos sólidos solúveis. Este comportamento é concordante com Bleinroth (1993). Segundo Chitarra \& Chitarra (1990), os sólidos solúveis aumentam em decorrência da hidrólise da protopectina em pectina solúvel e da hidrólise do amido em glicose e frutose.

Quanto ao amido, nota-se uma tendência de redução dos teores ao longo do armazenamento (Tabela 6), mas sem diferença entre os tratamentos ao final do armazenamento. Os teores médios para o amido em banana-prata variam, de acordo com as determinações de Rossignoli (1983) entre 22,80 a $25,92 \%$ na fruta verde e 2,3 a $3,4 \%$ na fruta madura, respectivamente. Os valores encontrados no presente trabalho foram próximos da faixa relatada pelo autor, ou seja, $18 \%$ na fruta verde (grau de coloração 1 - análise preliminar) e 3,58 a 4,61\% na fruta madura (grau de coloração 7).

É notável, porém que, tanto os valores de SST quanto os de amido confirmam a proposta de que as frutas climatizadas 1 dia após a colheita tenderam a apresentar um retardo no amadurecimento no $1^{\circ}$ dia de avaliação quando comparadas às frutas dos demais tratamentos, já que estas se apresentavam com maior porcentagem de amido e menor quantidade de sólidos solúveis.

Os dados de $\mathrm{pH}$ e acidez total titulável estão descritos nas Tabelas 7 e 8, respectivamente. Em relação ao comportamento da acidez total titulável houve uma tendência em sua diminuição durante o período de armazenamento, podendo ser associado ao aumento dos valores de $\mathrm{pH}$ no mesmo período. A acidez total titulável não foi influenciada pelas diferentes épocas de climatização e os valores encontrados neste experimento ficaram dentro da faixa dos teores encontrados por Carvalho et al. (1990) e Marriott \& Proctor (1978).

Os valores de $\mathrm{pH}$, como citado anteriormente, sofreram aumento durante o armazenamento das frutas. Esse aumento pode estar relacionado ao desdobramento do amido em açúcares redutores e sua conversão em ácido pirúvico provocada pela respiração das frutas (CHITARRA \& CHITARRA, 1990).

De acordo com Carvalho et al. (1989) e Rocha (1984), sabe-se que a acidez titulável para a banana cresce com o seu amadurecimento, e decresce quando a fruta se encontra muito madura ou senescente. Em contrapartida, 
os valores de $\mathrm{pH}$ diminuem após a colheita da banana e aumentam no final do amadurecimento ou início da senescência das frutas.

Levando-se em consideração este comportamento, nota-se que as frutas do tratamento $\mathrm{C}$ (climatizadas 3 dias após a colheita) tiveram seu amadurecimento acelerado em relação as frutas dos demais tratamentos, já que estas se apresentavam no $1^{\circ}$ dia de armazenamento com os menores valores de $\mathrm{pH}$. Os dados da Tabela 3 denotam esta afirmação, já que as frutas do Tratamento $\mathrm{C}$, no $1^{\circ}$ dia de avaliação se apresentavam mais amareladas do que as frutas dos tratamentos A e B. Contudo, as frutas do Tratamento A (climatizadas 1 dia após a colheita) mantiveram sua acidez titulável e pH até o $3^{\circ}$ dia de avaliação e apresentaram os menores valores de $\mathrm{pH}$ no $5^{\circ}$ dia de armazenamento, sugerindo um retardo em seu amadurecimento em relação às frutas dos demais tratamentos. Os dados de coloração das frutas do Tratamento A apresentados na Tabela 3 confirmam esta sugestão, já que até o $3^{\circ}$ dia de avaliação, enquanto o $\mathrm{pH}$ das frutas ainda estava decrescendo, o grau de coloração destas foi 6 , enquanto que para as frutas dos Tratamentos B e C foi 7.

TABELA 4 - Variação média da firmeza $\left(\right.$ lb.pol$\left.^{-2}\right)$ de banana-prata submetida à climatização*.

\begin{tabular}{|c|c|c|c|c|}
\hline \multirow{2}{*}{$\begin{array}{l}\text { Tratamentos } \\
\text { (dias entre colheita e } \\
\text { climatização) }\end{array}$} & \multicolumn{3}{|c|}{ Dia de armazenamento após climatização } & \multirow[b]{2}{*}{$\mathrm{CV}(\%)$} \\
\hline & $\mathbf{1}^{0}$ & $\mathbf{3}^{\mathbf{0}}$ & $5^{0}$ & \\
\hline A (1 dia) & $125,5 \mathrm{Aa}$ & $35,3 \mathrm{Ab}$ & $32,6 \mathrm{Ab}$ & 8,21 \\
\hline B (2 dias) & $50,7 \mathrm{Ba}$ & $36,1 \mathrm{Aa}$ & $40,0 \mathrm{Aa}$ & 30,22 \\
\hline $\mathrm{C}$ (3 dias) & $44,1 \mathrm{Ba}$ & $32,0 \mathrm{Aa}$ & $29,6 \mathrm{Aa}$ & 21,57 \\
\hline $\mathrm{CV}(\%)$ & 6,60 & 12,39 & 14,6 & \\
\hline
\end{tabular}

Médias seguidas de mesma letra maiúscula, na vertical, e minúscula na horizontal, não diferem estatisticamente, a nível de $5 \%$ probabilidade, pelo teste de Tukey.

* 1000 ppm de etil $5,18-19^{\circ} \mathrm{C}, 85 \%$ de UR.

TABELA 5 - Variação média de sólidos solúveis ( ${ }^{\circ}$ Brix) de banana-prata submetida à climatização*

\begin{tabular}{ccccc}
\hline $\begin{array}{c}\text { Tratamentos } \\
\text { dias entre colheita e } \\
\text { climatização) }\end{array}$ & \multicolumn{2}{c}{ Dia de armazenamento após climatização } & \\
\cline { 2 - 4 } & $1^{\mathrm{O}}$ & $3^{\text {o }}$ & $\mathrm{CV}(\%)$ \\
\hline $\mathrm{A}(1 \mathrm{dia})$ & $15,5 \mathrm{Bb}$ & $24,6 \mathrm{Ba}$ & $24,9 \mathrm{Aa}$ & 7,59 \\
$\mathrm{~B}(2$ dias $)$ & $21,3 \mathrm{Aa}$ & $25,4 \mathrm{Aa}$ & $25,7 \mathrm{Aa}$ & 9,53 \\
$\mathrm{C}(3 \mathrm{dias})$ & $21,3 \mathrm{Ab}$ & $25,3 \mathrm{ABab}$ & $26,6 \mathrm{Aa}$ & 8,25 \\
\hline $\mathrm{CV}(\%)$ & 7,68 & 1,30 & 2,71 & \\
\hline
\end{tabular}

Médias seguidas de mesma letra maiúscula, na vertical, e minúscula na horizontal, não diferem estatisticamente, a nível de $5 \%$ probabilidade, pelo teste de Tukey.

* 1000 ppm de etil $5,18-19^{\circ} \mathrm{C}, 85 \%$ de UR. 
TABELA 6 - Variação média do amido $(\%)$ de banana-prata submetida à climatização* .

\begin{tabular}{|c|c|c|c|c|}
\hline \multirow{2}{*}{$\begin{array}{l}\text { Tratamentos } \\
\text { (dias entre colheita e } \\
\text { climatização) }\end{array}$} & \multicolumn{3}{|c|}{ Dia de armazenamento após climatização } & \multirow[b]{2}{*}{ CV $(\%)$} \\
\hline & $\mathbf{1}^{\mathbf{0}}$ & $3^{0}$ & $5^{\circ}$ & \\
\hline A (1 dia) & $9,21 \mathrm{Aa}$ & 6,28 Aab & $4,60 \mathrm{Ab}$ & 18,00 \\
\hline B (2 dias) & $5,13 \mathrm{Ba}$ & 4,35 Aa & $4,61 \mathrm{Aa}$ & 25,35 \\
\hline $\mathrm{C}(3$ dias $)$ & $4,28 \mathrm{Ba}$ & $4,24 \mathrm{Aa}$ & $3,58 \mathrm{Aa}$ & 38,27 \\
\hline $\mathrm{CV}(\%)$ & 24,51 & 23,64 & 56,11 & \\
\hline
\end{tabular}

Médias seguidas de mesma letra maiúscula, na vertical, e minúscula na horizontal, não diferem estatisticamente, a nível de $5 \%$ probabilidade, pelo teste de Tukey.

* $1000 \mathrm{ppm}$ de etil $5,18-19^{\circ} \mathrm{C}, 85 \%$ de UR.

TABELA 7 - Variação média de pH de banana - prata submetida à climatização*.

\begin{tabular}{ccccc}
\hline \multirow{2}{*}{\begin{tabular}{c} 
Tratamentos \\
(dias entre colheita \\
\cline { 2 - 4 } climatização)
\end{tabular}} & $\mathbf{1}^{\mathbf{0}}$ & $\mathbf{3}^{\mathbf{0}}$ & $\mathbf{5}^{\mathbf{0}}$ & $\mathbf{C V}(\boldsymbol{\%})$ \\
\hline $\mathrm{A}(1 \mathrm{dia})$ & $4,40 \mathrm{Ab}$ & $4,34 \mathrm{Bb}$ & $4,70 \mathrm{Aa}$ & 1,96 \\
$\mathrm{~B}(2$ dias $)$ & $4,46 \mathrm{Ab}$ & $4,57 \mathrm{Ab}$ & $4,82 \mathrm{Aa}$ & 1,51 \\
$\mathrm{C}(3$ dias $)$ & $4,19 \mathrm{Ba}$ & $4,54 \mathrm{Aa}$ & $4,76 \mathrm{Aa}$ & 4,61 \\
\hline $\mathrm{CV}(\%)$ & 1,92 & 1,51 & 1,22 & \\
\hline
\end{tabular}

Médias seguidas de mesma letra maiúscula, na vertical, e minúscula na horizontal, não diferem estatisticamente, a nível de $5 \%$ probabilidade, pelo teste de Tukey.

* 1000 ppm de etil $5,18-19^{\circ} \mathrm{C}, 85 \%$ de UR.

TABELA 8 - Variação média da acidez titulável (g ácido málico. $100 \mathrm{~g}$ de polpa ${ }^{-1}$ ) de banana - prata submetida à climatização*.

\begin{tabular}{ccccc}
\hline \multirow{2}{*}{$\begin{array}{c}\text { Tratamentos } \\
\text { (dias entre colheita } \begin{array}{c}c \\
\text { climatização) }\end{array}\end{array}$} & $\mathbf{1}^{\mathbf{0}}$ & $\mathbf{3}^{\mathbf{0}}$ & $\mathbf{5}^{\mathbf{o}}$ & $\mathbf{C V}(\boldsymbol{\%})$ \\
\hline A (1dia) & $0,30 \mathrm{Aa}$ & $0,31 \mathrm{Aa}$ & $0,23 \mathrm{Aa}$ & 14,42 \\
$\mathrm{~B}(2$ dias $)$ & $0,32 \mathrm{Aa}$ & $0,27 \mathrm{Aab}$ & $0,21 \mathrm{Ab}$ & 10,39 \\
C (3 dias) & $0,32 \mathrm{Aa}$ & $0,29 \mathrm{Aab}$ & $0,23 \mathrm{Ab}$ & 11,59 \\
\hline CV $(\%)$ & 15,51 & 9,76 & 7,61 & \\
\hline
\end{tabular}

Médias seguidas de mesma letra maiúscula, na vertical, e minúscula na horizontal, não diferem estatisticamente, a nível de $5 \%$ probabilidade, pelo teste de Tukey.

* 1000 ppm de etil $5,18-19^{\circ} \mathrm{C}, 85 \%$ de UR. 


\section{CONCLUSÃO}

As modificações associadas ao amadurecimento são mais intensas e aceleradas em banana- prata climatizada 2 e 3 dias após a colheita, em comparação àquelas observadas nas frutas climatizadas 1 dia após a colheita. Entretanto, tal efeito é anulado a partir do $3^{\circ}$ dia de armazenamento em condição ambiente.

\section{REFERÊNCIAS BIBLIOGRAFICAS}

ASSOCIATION OF OFFICIAL ANALYTICAL CHEMISTS. Official methods of analysis of the AOAC. 13. ed. Washington, 1992. $1015 \mathrm{p}$.

BLEINROTH, E. G. Matéria-prima. In: ITAL. Banana. Campinas, 1993. 302 p.

BLEINROTH, E. W. Manuseio pós-colheita, classificação, embalagem e transporte da banana. In: SIMPÓSIO BRASILEIRO SOBRE BANANICULTURA, 1., 1984, Jaboticabal, SP. Anais... Jaboticabal: FCAVJ, 1984. p. 353-367.

BLEINROTH, E. W.; ZUCHINI, A. G.; POMPEO, R. M. Determinação das características físicas e mecânicas de abacate e sua conservação pelo frio. Coletânea Ital, Campinas, v. 7, n. 1, p. 29-81, 1976.

BOTELHO, R. V. Efeito do tratamento pós-colheita com cálcio na ocorrência de antracnose (Colletotrichum gloeosporioides Penz) e no armazenamento de goiabas (Psidium guajava L.). 1996. 122 f. Dissertação (Mestrado em Horticultura) - Faculdade de Ciências Agronômicas, Universidade Estadual Paulista, Botucatu, 1996.

BOTREL, N.; SILVA, O. F.; BITTENCOURT, A. M. Procedimentos pós-colheita. In: MATSUURA, F. C. A. U.; FOLEGATTI, M. I. S. (Eds.). Banana: pós-colheita. Cruz das Almas: Embrapa Mandioca e Fruticultura; Brasília, DF: Embrapa Informação tecnológica, 2001. p. 32-39. (Frutas do Brasil, 16).

CARVALHO, C. R. L. et al. Análise química de alimentos. Campinas: Instituto de Tecnologia de Alimentos, 1990. 121 p. (Manual técnico).

CARVALHO, H. A. et al. Qualidade da banana 'prata' previamente armazenada em filme de polietileno, amadurecida em ambiente com umidade relativa elevada: acidez, sólidos solúveis e taninos. Pesquisa Agropecuária Brasileira, Brasília, v. 24, n. 5, p. 495-501, 1989.

CASTRO, J. V. Maturação controlada de frutas. In:

Tecnologia de pós-colheita de frutas tropicais. Campinas: [s.n.], 1992. cap. 9, p. 93-102. (Manual técnico).

CHITARRA, A. B.; CHITARRA, M. I. F. Manejo póscolheita e amadurecimento comercial de banana. Pesquisa Agropecuária Brasileira, Brasília, v. 19, n. 6, p. 761-71, 1984.

CHITARRA, M. I. F. Características das frutas de exportação. In: GONGATTI NETO, A. et al. Goiaba para exportação: procedimentos de colheita e pós-colheita. Brasília, DF: EMBRAPA, 1996. cap. 1, p. 9-11. (Série publicações técnicas FRUPEX, 20).

CHITARRA, M. I. F.; CHITARRA, A. B. Pós-colheita de frutos e hortaliças: fisiologia e manuseio. Lavras: ESAL/ FAEPE, 1990. 293 p.

CHITARRA, M. I. F.; CHITARRA, A. B. Colheita e qualidade pós-colheita de frutas. Informe Agropecuário, Belo Horizonte, v. 17, n. 179, p. 8-18, 1994.

FAO. Faostat database query. Disponível em: $<$ http:// IWWW.fao.org/> A Acesso em: 9 set. 2004.

GOMES, F. P. Curso de estatística experimental. 12. ed. Piracicaba: Nobel, 1987. 467 p.

INSTITUTO BRASILEIRO DE GEOGRAFIA E ESTATÍSTICA. Pesquisa de orçamentos familiares 1995/ 96: primeiros resultados. Rio de Janeiro, 1997. 247 p.

INSTITUTO BRASILEIRO DE GEOGRAFIA E ESTATÍSTICA.Cidades@. Disponível em: < http:// |www.ibge.gov.bj > Acesso em: 20 jun. 2002.

ISO. Green bananas, ripening conditions. Genebra, 1977. $6 \mathrm{p}$.

LICHTEMBERG, L. A. Colheita e pós-colheita da banana. Informe Agropecuário, Belo Horizonte, v. 20, n. 196, p. 7390, 1999. 
MARRIOTT, J.; PROCTOR, F. J. Transportation and conservation of tropical fruits. Outlook on Agriculture, Bracknell, v. 9, n. 5, p. 233-239, 1978.

MOREIRA, R. S. Banana: teoria e prática de cultivo. Campinas: Fundação Cargill, 1987. 335 p.

PALMER, J. K. Biochemistry of fruits. In: HULME, A. C. The biochemistry of fruits and their products. London: Academic, 1981. p. 65-105.

ROCHA, J. L. V. Fisiologia pós-colheita de banana. In:SIMPÓSIO BRASILEIRO SOBRE BANANICULTURA, 1., 1984, Jaboticabal, SP.Anais... Jaboticabal: FCAVJ, 1984. p. 353-367.

ROSSIGNOLI, P. A. Atmosfera modificada por filmes de polietileno de baixa densidade com diferentes espessuras para conservação de banana 'Prata' em condições ambiente. 1983. 81 f. Dissertação (Mestrado em Agronomia) - Escola Superior de Agricultura de Lavras, Lavras, 1983.

SIGRIST, J. M. M. Transpiração. In: BLEINROTH, E. W. et al. Tecnologia de pós-colheita de frutas tropicais. 2. ed. Campinas: ITAL, 1992. p. 33-40.

SIMÃO, S. Tratado de fruticultura. Piracicaba: FEALQ, 1998. $760 \mathrm{p}$.

SIMMONDS, N. W. Los platanos. Barcelona: Blume, 1973. $539 \mathrm{p}$.

SOTO BALLESTERO, M. Bananos: cultivo y comercialización. San José: LIL, 1992. 674 p. 